\title{
Temperature Calculation in an Uncooled Low-pressure Stage of a Heavy-duty Gas Turbine Using Conjugate Heat Transfer Analysis
}

\author{
Hossein Salemkar ${ }^{1}$, Amir Poursamad $^{1}$, Reza Torabideh $^{2}$, Payam Savadkouhi $^{2}$ \\ ${ }^{1}$ Engineering and R\&D Department, MAPNA Turbine Engineering and Manufacturing Co. (TUGA) \\ Fardis, Karaj- I.R.IRAN \\ ${ }^{2}$ Engineering and R\&D Department, MAPNA Turbine Blade Engineering and manufacturing Co. (PARTO) \\ Fardis, Karaj- I.R.IRAN
}

\begin{abstract}
In this paper, conjugate heat transfer (CHT) simulation is performed for a low-pressure stage of MGT-70, a heavy-duty gas turbine (GT) manufactured by MAPNA Group. Although the vane and the blade are uncooled, CHT analysis is performed to assess the validity of using the fluid temperature of an adiabatic simulation as the uncooled vanes or blades temperature, and also to model the heat transfer between root or shroud and vane or blade profile. To compare the resultant temperatures of $\mathrm{CHT}$ and adiabatic flow analysis both simulations are done, using the same boundary conditions. The vane shroud extends over the blade tip, which is of free-standing type, and there is not a shroud segment. In fact, the vane and blade share the shroud. In order to predict the shroud temperature more accurately, the vane and the blade are simulated simultaneously as a stage using appropriate interfaces. A single vane CHT simulation is also performed to evaluate the effect of blade tip flow on the shroud temperature. Furthermore, the cavity above the shroud, containing the cooling and sealing flow, is also included in the model to better prediction of the shroud temperature. In addition, the rim cavity and the labyrinth seal under the vane platform are included in the model to better predict the vane platform temperature and to capture the effect of purge flows on vane and blade temperature.

Simulation results show that, although, the average bulk temperature of the profile in both CHT and adiabatic simulations are close to each other, there are great differences in temperature distribution over the suction side and pressure side. These differences are because of heat flux through the profile in CHT simulation, which results in a more realistic metal temperature distribution. Comparing the results of the single vane simulation and stage simulation no remarkable difference is observed in the temperature distribution, except for the shroud region above blade tip. This reveals that, although, the tip leakage flow is better captured in the stage simulation, it is only useful when the shroud temperature is of interest and it does not affect the vane profile temperature distribution. Finally, the inclusion rim cavity and labyrinth seal in the simulation helps to predict the mass flow distribution of purge flows and the effect of these flows on platform temperature distribution in vane and blade.
\end{abstract}

\section{INTRODUCTION}

As temperature distribution over vanes and blades profile play key role in life prediction, it is important to find the distribution more accurately, even in uncooled stages. Throughout the history of gas turbine development, there has been a continuous increase in the turbine inlet temperature, as an important factor affecting the specific work and efficiency. The main barrier to this increase has been the temperature limits of the hot gas path components, most importantly turbine section vanes and blades. In order to tackle this issue, beside the researches to develop advanced material, advanced coatings, and improved cooling technologies, there have been ongoing efforts to predict the vanes and blades metal temperature as accurately as possible. This is due to the fact that the more accurate metal temperature prediction will result in less conservative designs.

Among many approaches developed for numerical prediction of turbine vanes and blades temperature, Conjugate Heat Transfer (CHT) analysis has attracted the attention of many researchers during the last decade. There were valuable efforts from primary CFD analysis of turbine components to very advanced high fidelity simulations with great super computers for better understanding of events occurs inside and outside parts of any vanes and blades.

Preliminary 3D conjugate heat transfer analysis of a radially cooled gas turbine vane has been performed to find metal temperature distribution of the linear NASA-C3X cascade, for which experimental data are available. the blade is internally cooled by air through ten radially oriented circular cross section channels. Results confirm the significant role of transition in predicting heat transfer [1]. One of the lead studies about CHT analysis of film cooling was in conceptual design and cooling blade development of a $1700^{\circ} \mathrm{C}$-class high-temperature gas turbine in the ACRO-GT-2000 project [2]. In the way of studying the parameters which affect the temperature distribution of the vanes and blades, the flow and thermal fields exiting gas turbine combustors became as point of interest. The goal of those works was to investigate the effects of engine representative combustor exit profiles on high pressure turbine vane aerodynamics and heat transfer. The results indicate that the inlet total pressure profiles affected the aerodynamic loading by as much as $10 \%$ [3]. With more computational hardware possibilities and capabilities of doing high fidelity simulations, more turbine stages were simulated during the time. To catch up this milestone, a conjugate heat transfer analysis methodology has been defined and applied to an Air Force film cooled turbine vane consisting of 648 cooling holes. An unstructured computational mesh with 24 million elements was used to model both the fluid and metal sides of the turbine vane covering 648 film holes [4]. Besides all efforts to use more fidelity in simulation files, there have been some efforts to use different turbulence models to find better prediction of temperature distribution and being close to measurements [5]. Due to advancements made in computational technology, secondary flow behaviour became as point of interest. Some researches discussed a robust CFD based methodology to validate the complex gas turbine blade cooling design using detailed 3D flow \& conjugate heat transfer analysis. Both primary and secondary flow domains along with blade metal are considered in one single integrated CFD model [6]. Moreover, conjugate calculations have shown a considerably decreased surface temperature for a whole geometry with a broken-away TBC, but could not 
attribute this effect conclusively to the decreased surface or the changed fluid flow conditions resulting from the changed outlet geometry [7].

An uncooled stage of MGT-70, a heavy-duty gas turbine (GT) manufactured by MAPNA Group, has been chosen for the present research. First, a CHT analysis is done to determine the metal temperature distribution in the vane and blade and also the fluid flow behaviour around vane and blade; then, an adiabatic calculation is performed to investigate the differences in temperature distribution between adiabatic and CHT calculation. Finally, a single row calculation is done to study the effects of blade existence on vane profile temperature distribution.

\section{NOMENCLATURE \\ $\mathrm{ASC}=$ Adiabatic Stage Calculation \\ $\mathrm{CHT}=$ Conjugate Heat Transfer \\ $\mathrm{CRC}=$ CHT Row Calculation \\ $\mathrm{CSC}=\mathrm{CHT}$ Stage Calculation \\ HTC $=$ Heat Transfer Coefficient \\ SAS $=$ Secondary Air System \\ $\mathrm{P}_{\mathrm{t}}=$ Total Pressure \\ $\mathrm{T}_{\mathrm{t}}=$ Total Temperature \\ $\mathrm{T}_{\mathrm{s}}=$ Static Temperature}

\section{GEOMETRY MODELLING}

Figure 1 shows that stage 4 of the MGT-70 has been chosen for this research. Since, vane and blade share the shroud and there is no shroud segment, it is recommended to solve the vane and blade simultaneously in one integrated simulation file.

The plan shows that there is a cavity in upper part of the vane shroud where cooling air flows through it and helps to decrease bulk temperature of the shroud. Cooling air enters the cavity from the upper side and exit laterally. This flow regime will result in complicated temperature distribution which cannot be replaced by heat transfer coefficient. Therefore this cavity modelled and is known as Upper Cavity in this article.

The rim cavity and labyrinth seal zone in lower part of the vane affect temperature distribution over vane and blade platform. Previous blade (Blade 3) root cooling air will enter this zone and divides into two parts. One part will flow through labyrinth seal and leak into hot gas path after vane 4 and before blade 4 . The second part will leak into gas path before vane 4 and after blade 3 . Therefore labyrinth seal and rim cavity added to the model which include blade 3 cooling air inlet.

Vane and blade hot gas flowpath is made in order to hub and shroud curve line. After blade flowpath, there is also a stationary outlet domain which is part of exhaust domain and helps to predict blade outlet pressure and temperature profile more accurately.

Finally, there are 6 fluid and solid domains which is made and connect to each other with appropriate interfaces model.

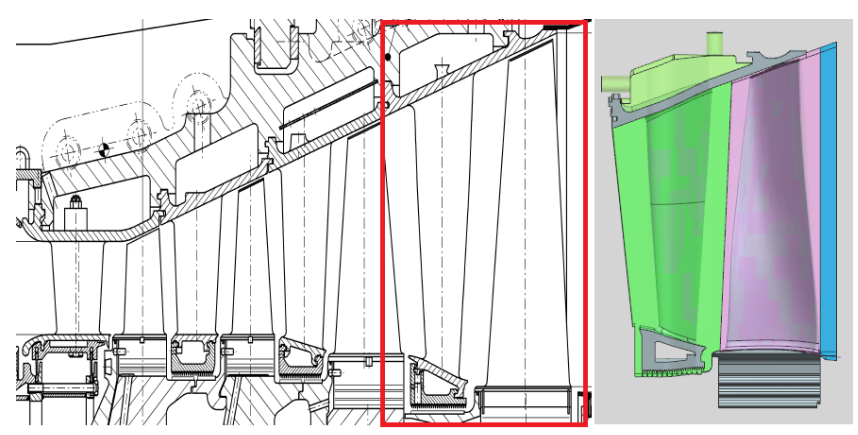

Fig.1 MGT-70 Stage 4 model

\section{GRID GENERATION}

All 6 domains meshed with tetrahedral cell and prism layer in critical areas. Figure 2 shows the vane solid domain grid network. Mesh density varies through the solid to capture curvatures as good as possible. It is shown that in areas like trailing edge, front area of platform and labyrinth seals the mesh density are more than other parts of the domain. There is also prism layer setup on vane profile with first layer height of $0.02 \mathrm{~mm}$ and total 5 layers. Figure 3 also shows the platform and blade tip in solid domain. Prism layer setup in blade profile is the same as vane profile to predict temperature gradient normal to surfaces from suction side to pressure side more smoothly.

Vane and blade fluid domains have the same surface setup of solid domains except for prism layers. There are 12 prism layers in both vane and blade fluid domain with first layer height $0.001 \mathrm{~mm}$ in solid-fluid interfaces to capture the aerodynamic and heat transfer boundary layer more realistic. With this setup, the $\mathrm{Y}+$ will be below 1 for each fluid domain.

In upper cavity fluid domain, there is also 12 prism layer like hot gas domains. This is because of temperature distribution prediction in shroud segment. Except for the global cell size in stationary outlet domain which should be in the same order of magnitude with blade fluid domain, this domain does not have any specific consideration for meshing setup.

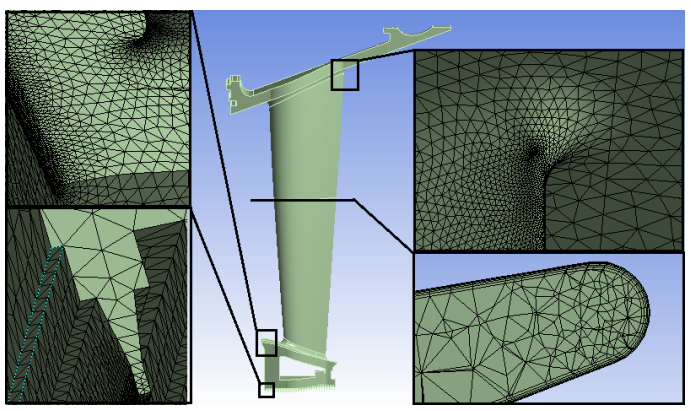

Fig. 2 Generated mesh for vane solid domain

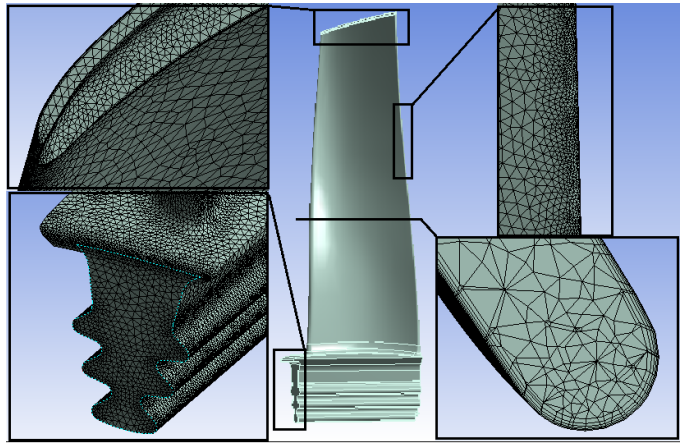

Fig. 3 Generated mesh for blade solid domain

There was some effort in studying grid independency in whole domain. All 6 domains and specially vane and blade hot gas domain were meshed with 4 different setups and volume average metal temperature has been traced through these calculations which are shown in Fig. 4. As it can be seen, the volume average of metal temperature in both vane and blade is not changing any more. Therefore, third setup is selected as final setup for grid generation.

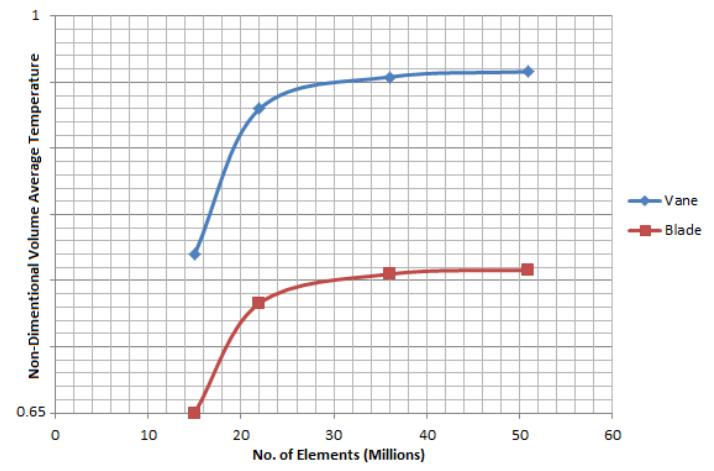

Fig.4 Grid independency 
Therefore total number of 36 million elements is generated for the whole simulation file where Table 1 shows each domain cell number one by one.

Table. 1 Number of elements in each domain

\begin{tabular}{|l|c|}
\hline Domain & Number of Elements \\
\hline Vane (Solid) & 4506641 \\
\hline Vane (Fluid) & 15503453 \\
\hline Blade (Solid) & 3235961 \\
\hline Blade (Fluid) & 11823858 \\
\hline Upper Cavity & 1404899 \\
\hline Stationary Outlet & 185284 \\
\hline Total & 36660096 \\
\hline
\end{tabular}

\section{COMPUTATIONAL SETUP}

A steady state RANS modelling and SST turbulence model [8] with automatic wall treatment approach performed for fluid simulation. The purpose of automatic wall treatments is to make results insensitive with respect to wall mesh refinement [9]. The Y+ maintained below 1 for satisfaction of SST turbulence model. Gas and metal properties are modified in specific heat transfer, thermal conductivity and viscosity as a function of temperature.

Since CHT calculations are highly dependent of boundary conditions and maximum temperature in solid and temperature distributions will vary easily, it is important to define all boundary conditions as real as possible. Therefore, a $3 \mathrm{D}$ multistage calculation is done to find radial distributions for $\mathrm{P}_{t}, \mathrm{~T}_{\mathrm{t}}$ and flow angle. Total pressure and temperature boundary conditions for vane flowpath inlet and static pressure for stationary outlet are shown in Figs5-7.

Inlet Pt

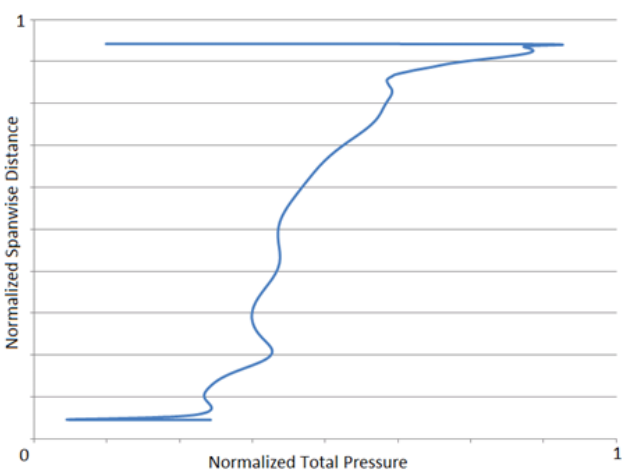

Fig.5 Normalized total presseure boundary condition for vane inlet

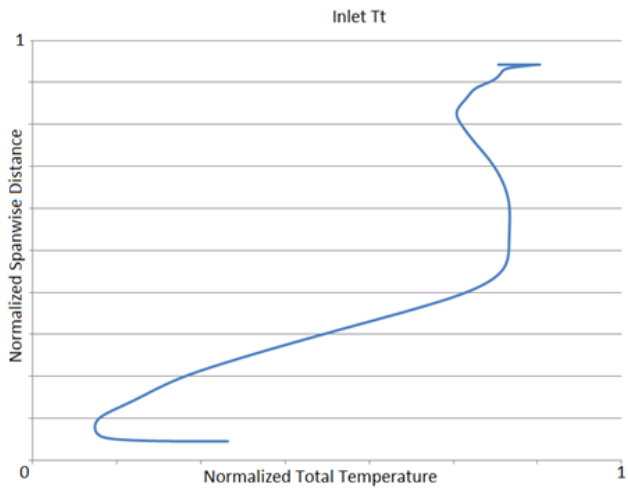

Fig.6 Normalized total temperature boundary condition for vane inlet

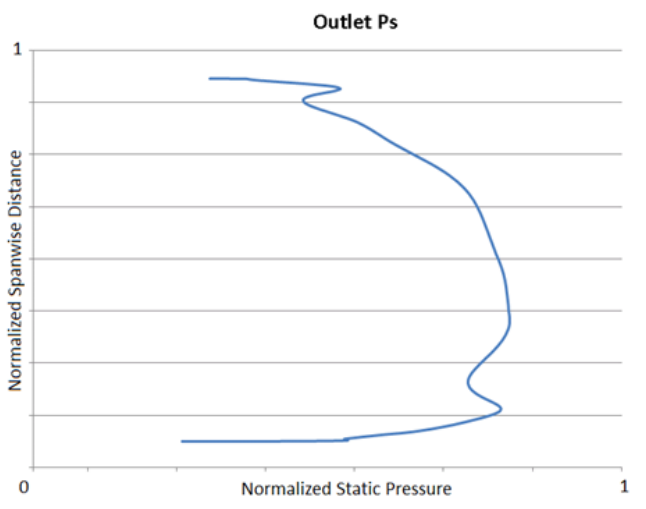

Fig. 7 Normalized static presseure boundary condition for blade outlet

There was also a 1D flange to flange calculation for Secondary Air System (SAS) to find pressure and temperature around stage 4 for cooling consumptions. Therefore a 1D code has been extended which calculate the flow properties along the path from compressor bleed holes to the seal ring and every vane upper cavity. Therefore this calculation determines the total pressure and temperature for upper cavity and blade 3 root cooling inlets. The stage domain has three inlet boundary conditions for hot gas, upper cavity and blade 3 root cooling. $P_{t}$ and $T_{t}$ have been set in hot gas and upper cavity inlet. Flow angle also set in hot gas inlet for better capturing the stagnation point around leading edge. It should be noted that all boundary conditions in hot gas inlet are radial distribution hub to shroud circumferential averaged. For blade 3 root cooling inlet only $\mathrm{T}_{\mathrm{s}}$ and mass flow are set for convergence considerations. Stage outlet is located in stationary outlet domain with circumferential average static pressure.

Connections between Vane-Blade fluid domains and Blade-Stationary Outlet domains defined in mixing plane approach. Mass flow is defined for upper cavity outlet. Figure 8 shows all three inlets and two outlets boundary surfaces around simulation file. Interfaces between fluid and solid domains are defined in general grid interface approach. Blade domain rotates with 3000 RPM and connections between upper side of blade fluid domain and vane solid domain is performed with frozen rotor approach.

Since, there is not any fluid domain around blade root; then heat transfer coefficients and static temperature used to predict blade root heat flux from solid to root cooling air. The HTC also derived from SAS calculations and channel approximation method.

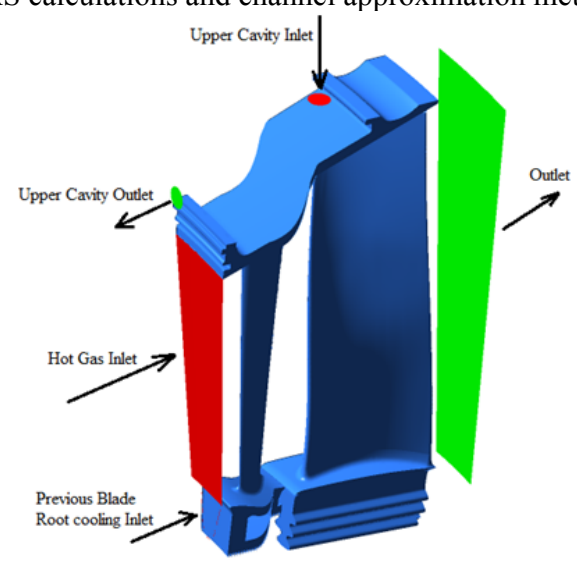

Fig. 8 All inlet and outlet locations in simulation file

\section{RESULTS \& DISCUSSIONS}

Temperature distribution play key role in life analysis, and high fidelity simulations help to find more realistic distributions through metal. For better understanding of the temperature distribution through vane and blade metal of an uncooled stage, first, CHT 
Stage Calculation (CSC) of stage 4 is done to discover all hot gas and cooling air behaviours around vane and blade. Second, an Adiabatic Stage Calculation (ASC) without any solid domain and upper cavity will be done to compare with CHT calculation and find out about differences in maximum and surface temperature distribution of these two calculations. Finally, a single vane CHT calculation without blade domain is performed to compare temperature distribution through vane profile with CHT stage calculation. In other words, this simulation helps to figure out about blade existence in one CHT integrated file simulation effects on vane profile temperature. This calculation will be known as CHT Row Calculation (CRC). Table 2 Shows that each calculation include any part of the simulation. In this table:

$\mathrm{VF}=$ Vane Flowpath

$\mathrm{BF}=$ Blade Flowpath

$\mathrm{VS}=$ Vane Solid

$\mathrm{BS}=$ Bladesolid

$\mathrm{UC}=$ Upper avity

$\mathrm{LS}=$ Labyrinth Seal

Table. 2 Differences between three calculations

\begin{tabular}{|l|r|r|r|r|r|r|}
\hline & VF & BF & VS & BS & UC & LS \\
\hline CSC & $\checkmark$ & $\checkmark$ & $\checkmark$ & $\checkmark$ & $\checkmark$ & $\checkmark$ \\
\hline ASC & $\checkmark$ & $\checkmark$ & & & & $\checkmark$ \\
\hline CRC & $\checkmark$ & & $\checkmark$ & & & \\
\hline
\end{tabular}

It should be noted that all calculations have the same boundary conditions for vane inlet flowpath. For outlet boundary conditions, CSC and ASC have the same boundary condition and CRC has its own static pressure for outlet from multistage calculation.

\section{Reference CHT Stage Calculation}

SST Turbulence model needs to maintain $\mathrm{Y}+$ over vane and blade below one to predict heat flux and temperature distributions properly. Figure 9 and 10 show Y+ contours over vane and blade profile which is in high importance. It shows that the maximum value for vane is 0.8 and for blade is 0.6 which is acceptable for SST model.
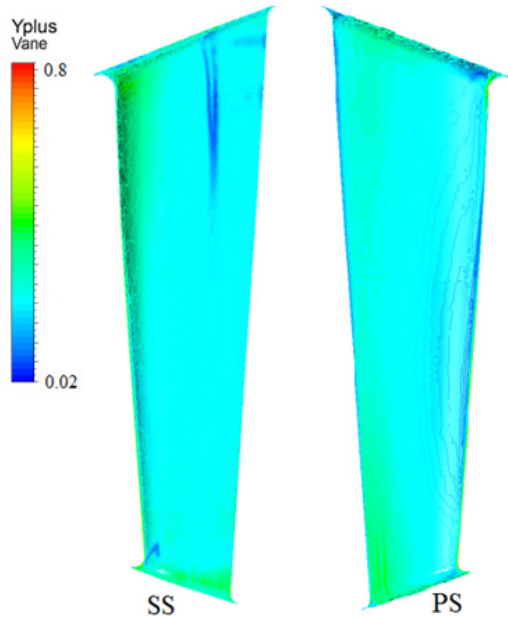

Fig. $9 \mathrm{Y}+$ contour in vane profile

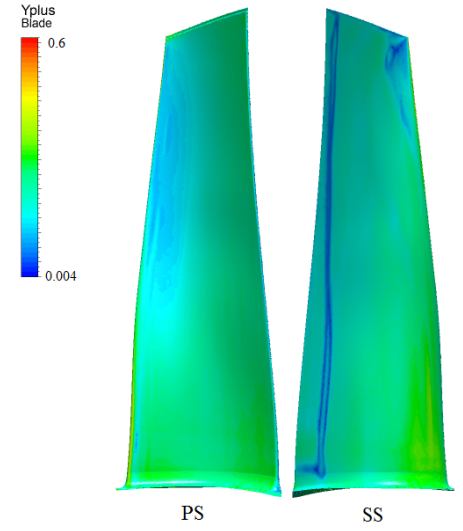

Fig. $10 \mathrm{Y}+$ contour in blade profile

Figure 11 shows the non-dimensional temperature distribution over the whole vane solid domain which includes labyrinth seal part. It should be noted that the temperature distribution is non-dimentionalized in all figures of this paper with local maximum temperature. It represents that maximum temperature in vane profile is located in leading edge and beginning of the shroud which is because of the flow angle at stage inlet.

There is temperature gradient in lower part of the vane platform and in labyrinth seal zone which is because of the blade 3 root cooling inlet in vane fluid domain. The schematic cooling air flow from blade 3 root to the main hot gas is demonstrated in Fig. 12. There are two routes for blade 3 root cooling and it is important to find mass flow rate in each one, because it might change the temperature distribution in labyrinth seal and platform. Table 3 shows that only $11.5 \%$ of the whole blade 3 cooling air will flow through rout 2 and $88.5 \%$ will flow through rout 3 and penetrate to the hot gas. Despite root cooling air is below $0.3 \%$ of the whole hot gas mass flow rate and only $11.5 \%$ of this air will flow over vane platform, but it has a great effect in platform temperature distribution. Figure 13 illustrates the streamline and static temperature contour over vane platform. It reveals that portion of the cooling air which penetrates to the hot gas and flow over the platform will change and reduce the temperature in this region.

Finally, Fig. 14 shows the non-dimensional temperature distribution inside the solid at Span 50\%. It reveals that leading edge has the maximum temperature as it was expected. Besides, there is heat flux from pressure side to the suction side of the vane and the differences between these two sides are almost 15K.

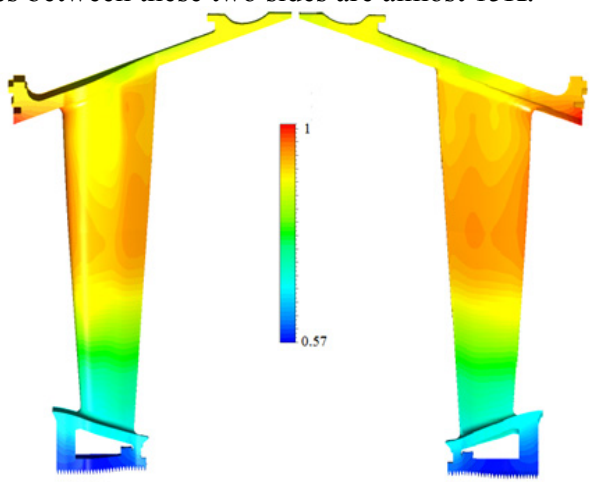

Fig. 11 Non-dimensional static Temperature contour in vane solid domain 


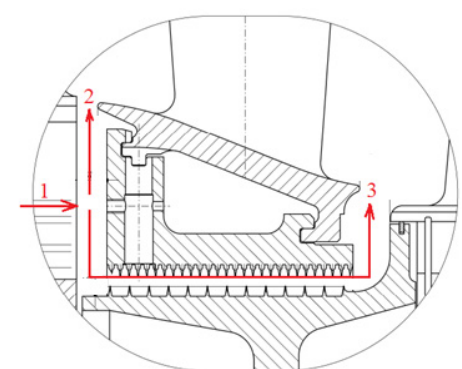

Fig. 12 Blade 3 root cooling air division in labyrinth seal zone

Table. 3 Mass flow distributions in labyrinth seal zone

\begin{tabular}{|l|c|}
\hline & Mass flow (\%) \\
\hline Rout 2 & 11.5 \\
\hline Rout 3 & 88.5 \\
\hline
\end{tabular}

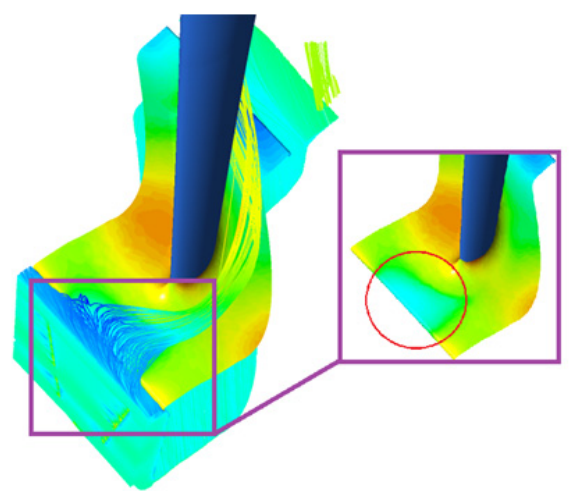

Fig. 13 Root cooling air flow effects over vane platform

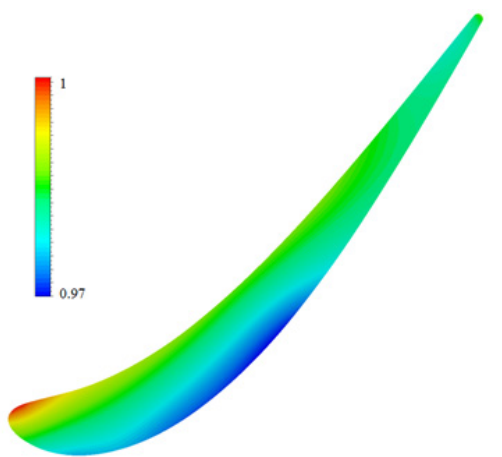

Fig. 14 Non-dimensional vane static temperature in Span 50\%

Figure 15 indicates the non-dimensional static temperature distribution over blade solid domain. Beside leading edge that has maximum temperature, blade tip also located in hot zone. Temperature distribution inside blade metal in Span $50 \%$ is illustrated in Fig. 16.

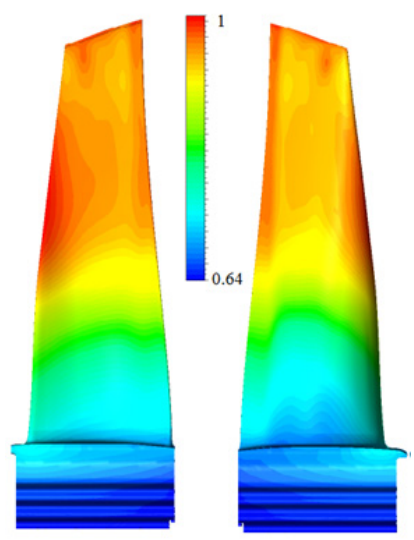

Fig. 15 Non-dimensional static Temperature contour in blade solid domain

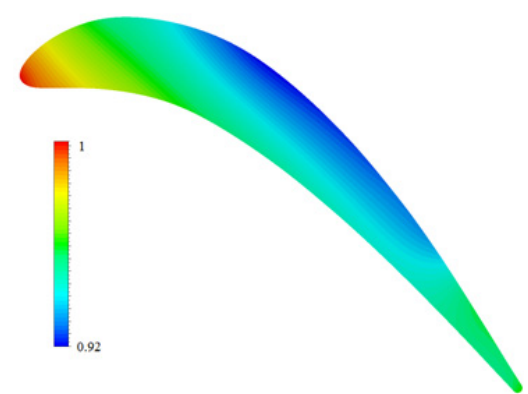

Fig. 16 Non-dimensional blade static temperature in Span 50\%

Previously in geometry modelling, it was noted that upper cavity has a cooling role in upper part of the shroud and it will reduce the temperature distribution over shroud surface. Figure 17 shows the exact location of the upper cavity fluid domain. There is an inlet in upper part and an outlet in left side of the cavity. It is expected that this configuration has an impingement effect in shroud surface and it can be seen in Fig. 18. This figure shows that there is a cold zone in central part of the shroud which seems to be impingement effect. The Upper cavity domain has complicated flow which make it impossible to find an equivalent HTC and static temperature to simplify the simulation and eliminate the Upper cavity domain. Therefore, it is better to model this region to find temperature distribution over shroud part more accurately. To easily figure out about the fluid flow inside this cavity, Fig. 19 shows the 2D projected streamline inside cavity. In this figure, Zone A is the impingement region.

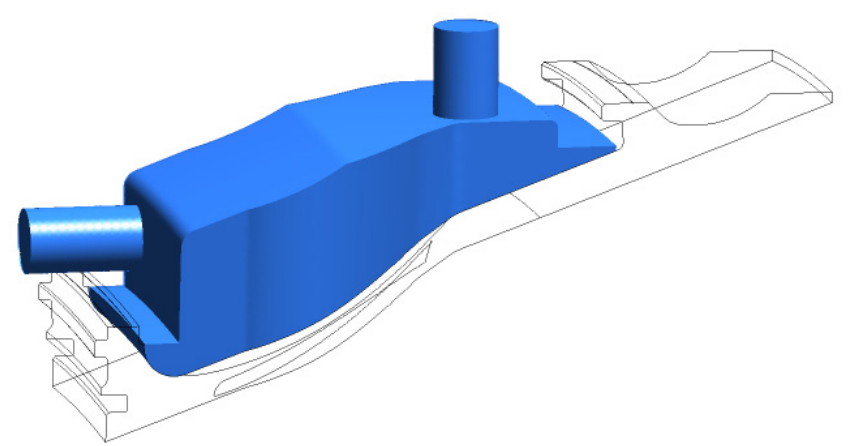

Fig. 17 Upper cavity domain location

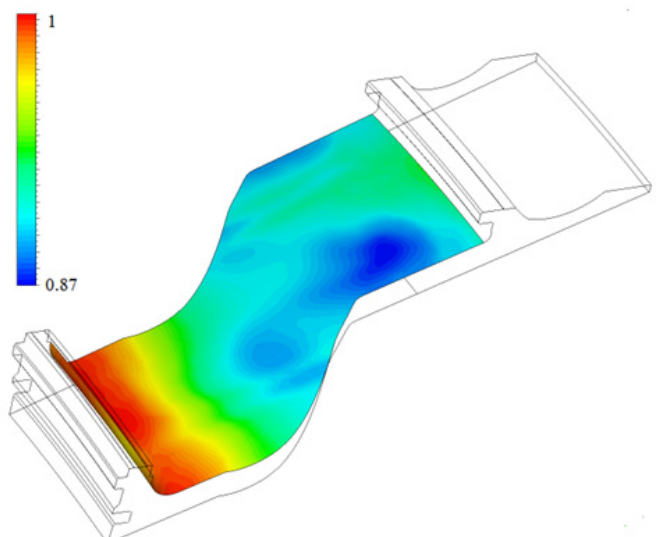

Fig. 18 Non-dimensional static Temperature contour on upper side of shroud 


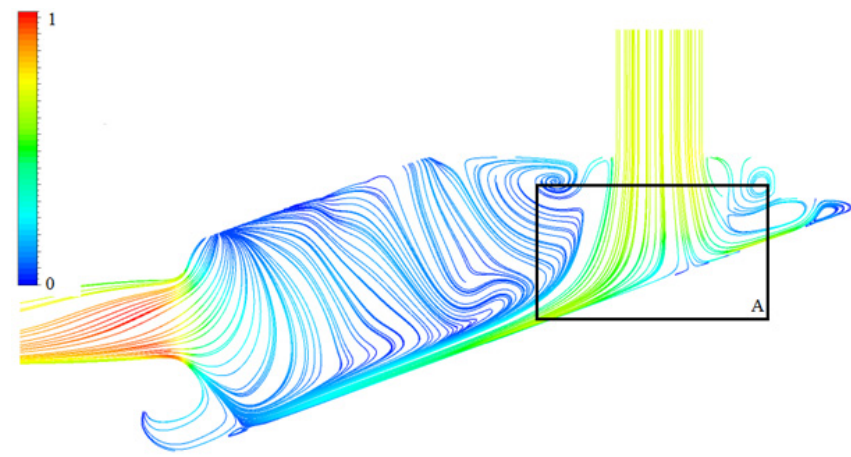

Fig. 19 2D projected streamline in upper cavity domain

\section{Adiabatic Stage Calculation}

An adiabatic stage calculation has been performed to compare surface temperature distribution over vane and blade profile. For this calculation all Boundary conditions for hot gas inlet, blade 3 root cooling inlet and outlet was kept the same as stage CHT calculation and just vane and blade solid domains and Upper cavity were eliminated from the simulation file. Figure 18 shows that the most important effect of upper cavity is captured in vane shroud above blade 4 and this is because of the impingement phenomena. The impingement area is far from vane profile and it has some negligible effect on vane profile temperature distribution. Therefore upper cavity and its effect on vane profile temperature distribution could be eliminated from adiabatic stage calculation. Figures 20 and 21 shows the adiabatic surface temperature of vane and blade. These figures reveal that the temperature distributions are totally different between $\mathrm{CHT}$ and adiabatic stage calculation.

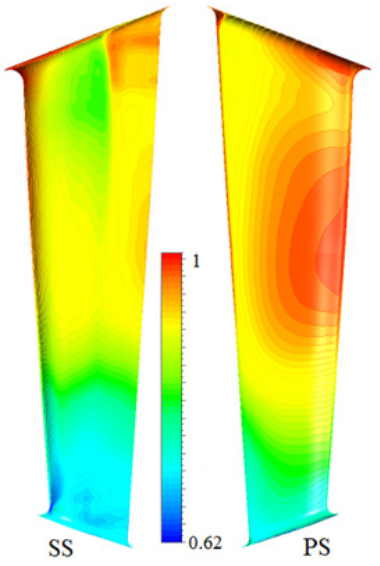

Fig. 20 Non-dimensional static temperature distribution through vane profile

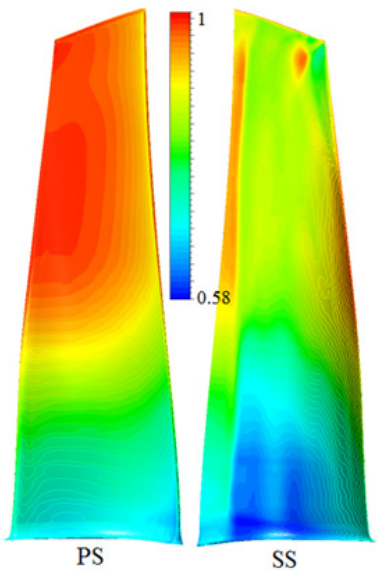

Fig. 21 Non-dimensional static Temperature distribution through blade profile
For better understanding of these differences and make it measurable, static temperature around a line in 3 span of $10 \%, 50 \%$ and $90 \%$ extracted from both CHT and adiabatic calculation and compared to each other. Figure 22.a-c shows the difference between CHT (Blue line) and adiabatic calculation (Red Line) in various spans of the vane profile. This figure reveals that the difference between suction and pressure side in adiabatic calculation are much more than CHT calculation. In other words, pressure side in adiabatic calculation has higher temperature than CHT stage calculation and suction side has lower temperature than CHT calculation. This figure shows that there is an abnormality around trailing edge which is negligible in span $10 \%$ and notable in span $90 \%$. This abnormality is because of the normal shock which is occurred in upper part of the vane profile. This shock will increase the static temperature in blade suction side instantly.

All these facts reveal that temperature distribution over vane profile is not realistic at all because it shows a great difference between suction and pressure side around $60 \mathrm{~K}$, while CHT calculation shows that they have only $15 \mathrm{~K}$ difference. This huge difference in pressure and suction side might results in failure during life analysis while real engine shows that there is not any failure in this stage even after $100000 \mathrm{hrs}$.

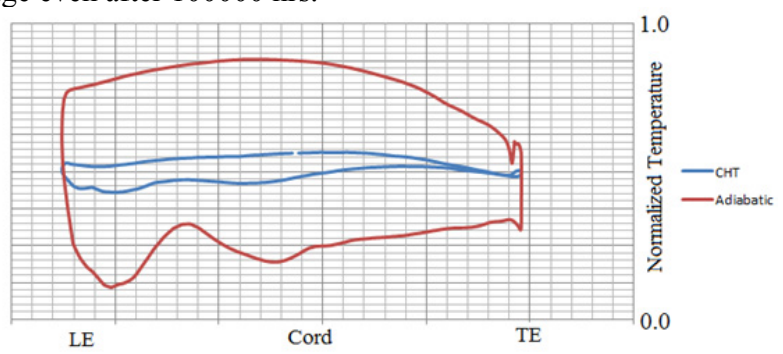

a) Vane static Temperature in Span $10 \%$

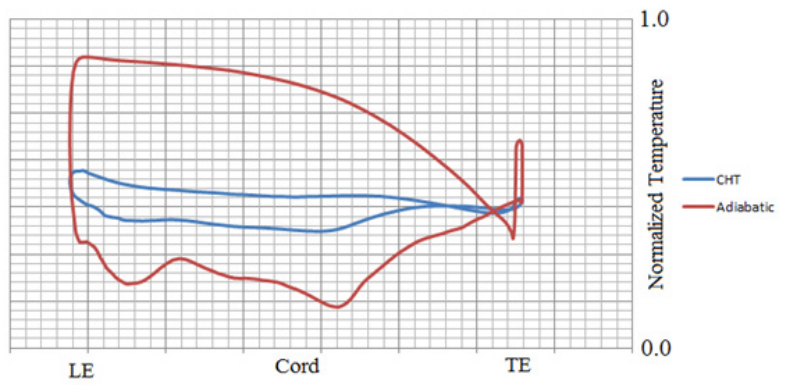

b) Vane static Temperature in Span $50 \%$

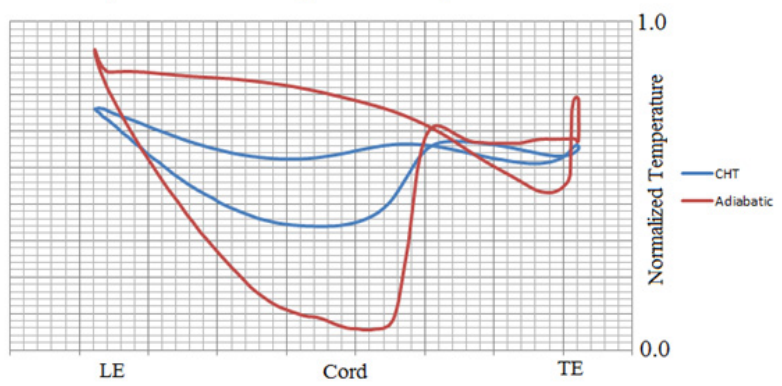

c) Vane static Temperature in Span $90 \%$

Fig. 22 ASC \& CSC static temperature distribution through vane profile in 3 spans of $10 \%, 50 \%, 90 \%$

All the analysis has been repeated for blade domain. It means that, temperature on the line of 3 various span of $10 \%, 50 \%$ and $90 \%$ were extracted from CHT calculation and compared to adiabatic calculation. Figure 13.a-c shows the temperature differences between these two analyses. It has been shown that normal shock near the trailing edge from platform to blade tip changed the temperature distribution over all spans. It seems that blade existence 
will result in heat flux from pressure to suction side and from hot areas of profile and platform to the cooler areas of blade root. These comparisons between CHT and Adiabatic calculations reveal that CHT calculations of uncooled stages are inevitable.

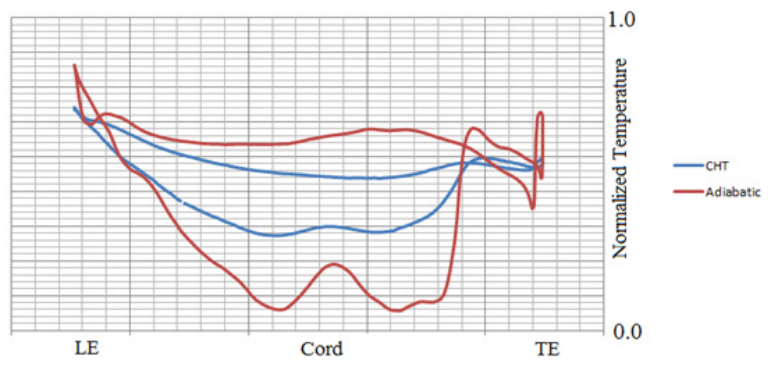

a) Blade Static Temperature in Span $10 \%$

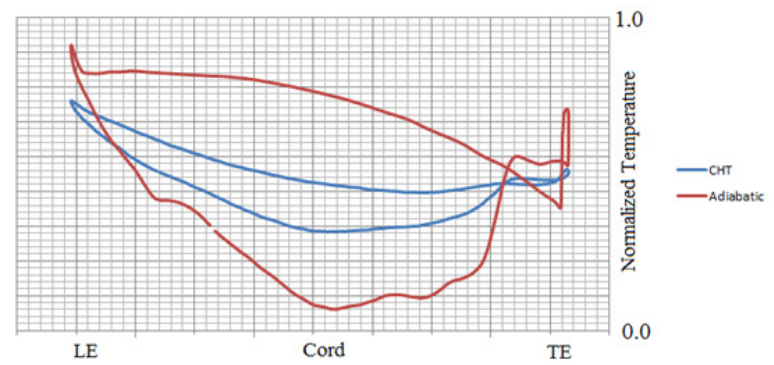

b) Blade Static Temperature in Span $50 \%$

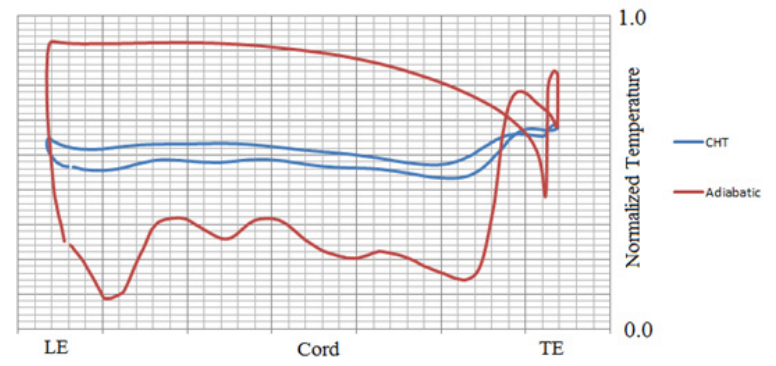

c) Blade Static Temperature in Span $90 \%$

Fig. 23 ASC \& CSC static temperature distribution through blade profile in 3 spans of $10 \%, 50 \%, 90 \%$

\section{CHT Row Calculation}

In those machines that vane and blade share the shroud and there is not any shroud segment, CHT analysis of vane has some uncertainties because of the outlet location in hot gas flowpath. In those calculations that vane only is the point of interest; the outlet should be in middle of the shroud part. It is shown in Fig. 24 that part of the shroud which is located above blade tip does not have any interfaces with fluid domain. This area should have HTC to simulate the real situation or it could be define as an adiabatic wall in worst condition. Using adiabatic wall is the easiest boundary condition for the shroud part above blade tip, but it will not predict the temperature distribution through the vane shroud. CHT row Calculation (CRC) has been performed to compare the temperature distribution over vane profile with CHT Stage Calculation (CSC).

Therefore, blade solid and fluid domain beside Stationary Outlet Domain has been removed from simulation file and only vane solid and fluid domain with its upper cavity domain remained active. Figure 24 shows the simulation domain completely. To compare CRC and CSC analysis, all the boundary conditions of CRC kept the same as CSC and only outlet conditions extracted from CSC and setup here. For better understanding of the differences between these two analyses, temperature distribution over three spans of $10 \%, 50 \%$ and $90 \%$ extracted and compared to each other.

Figure 25.a-c shows the temperature distribution over three different spans. It can be seen that stage analysis (Blue Line) does not have major differences with Row analysis (Red Line) in every specific span. This fact reveals that if only temperature distribution over vane profile is the point of interest and shroud temperature was not important, CRC and CSC do not have serious differences in static temperature. On the other hand, in CRC calculation, the time for conducting the whole simulation such as modeling, grid generation and calculation is two-third of CSC and it would be very helpful in time management of the project. Therefore, it is highly recommended to use $\mathrm{CRC}$ for the purpose of finding temperature distribution only over vane profile.

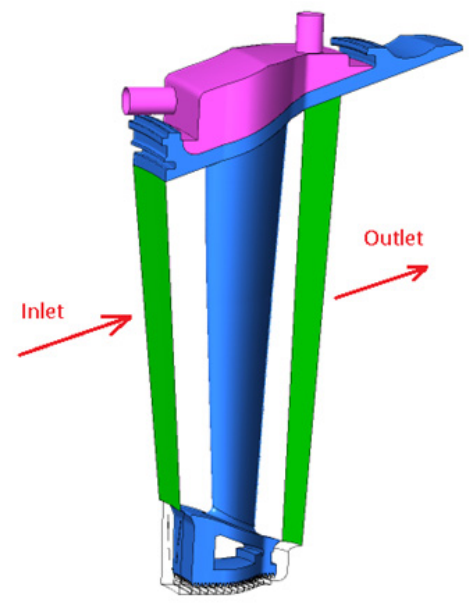

Fig. 24 CHT row calculation model

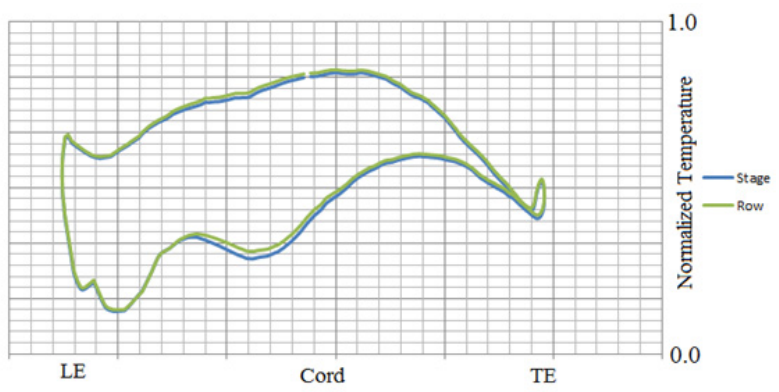

a) Static Temperature in Span 10\%

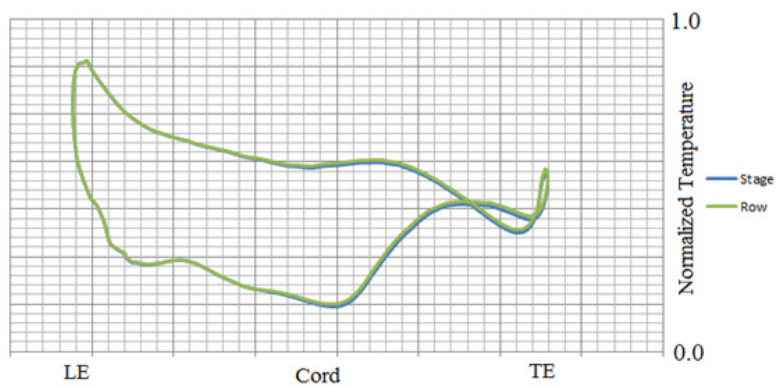

b) Static Temperature in Span 50\%

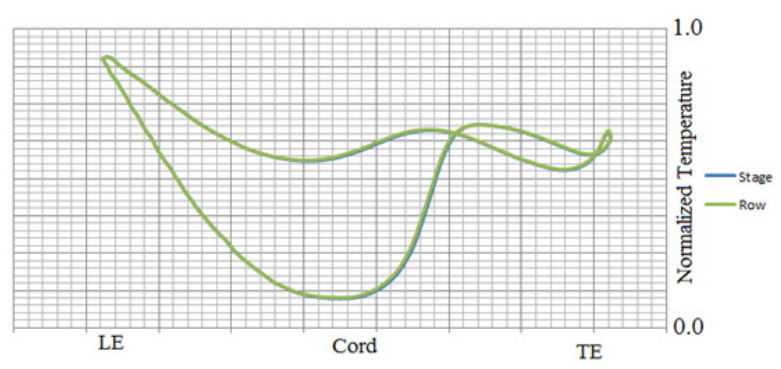

c) Static Temperature in Span $90 \%$

Fig. 25 CRC \& CSC static temperature distribution through vane profile in 3 spans of $10 \%, 50 \%, 90 \%$ 


\section{Conclusion}

In this research an uncooled stage of the MGT-70 heavy-duty industrial gas turbine has been simulated with CHT analysis and the following conclusions have been reached:

1. Using upper cavity fluid domain helps to predict temperature distribution over vane shroud more accurately.

2. Upstream blade root cooling air which enters the labyrinth seal fluid zone have great influence in platform and labyrinth seal temperature distribution and it is recommended to model it in fluid domain.

3. Temperature distribution over vane profile in CHT stage analysis is totally different from Adiabatic Stage Analysis. It seems that for realistic life analysis, a CHT analysis is required for uncooled blades as well.

4. For such gas turbines as MGT-70, where vane and blade share the shroud and there is not any shroud segments, it is possible to simulate the vane with its own flowpath without blade, and the boundary condition imposed on the shroud part above blade tip does not have any specific effect in temperature distribution over vane profile.

\section{ACKNOWLEDGMENT}

This work has been financially supported by MAPNA Group R\&D department under contract RD-RPI-90-16.

\section{REFERENCES}

[1] Facchini, B., Magi, A., Scotti Del Greco, A., 2004, "Conjugate Heat Transfer Simulation of A Radially Cooled Gas Turbine Vane," Proceedings, ASME Turbo Expo 2004, Land, Sea, and Air, GT2004-54213.

[2] E., Takehashi, T., Sato, M., Koyama, M., Ninomiya, T., 2005, "Conceptual Design and Cooling Blade Development of $1700^{\circ} \mathrm{C}$ Class High-Temperature Gas Turbine," Journal of Engineer-ing for Gas Turbines and Power, Vol. 127, pp 358-368.

[3] Barringer, M. D.,Thole, K. A., Polanka, M. D., 2009, " Effects of Combustor Exit Profiles on Vane Aerodynamic Loading and Heat Transfer in a High Pressure Turbine," Journal of Turbomachinery, Vol. 131, pp .....

[4] Ni, R., Humber, W., Fan, G., Johnson, P., Downs, Jim., Clark, J.P., Koch, P.J., 2011, "Conjugate Heat Transfer Analysis Of A Film-Cooled Turbine Vane," Proceedings, ASME Turbo Expo 2011, Vancouver, British Columbia, Canada, GT2011-45920.

[5] Ho, K., Urwiller, C., Konan, S., Liu, J., Aguilar, B., 2012, "Conjugate Heat Transfer Analysis For Gas Turbine Cooled Stator," Proceedings, ASME Turbo Expo 2012, Copenhagen, Denmark, GT2012-68196.

[6] Kathiravan, S., Prosperis, R., Ciani, A., 2013, "Numerical Investigation Of Flow And Heat Transfer In Gas Turbine Serpentine Passage Cooling And Comparison With Experimental Data," Proceedings, ASME Turbo Expo 2013, San Antonio, Texas, USA, GT2013-94666.

[7] Bohn, D., Krewinkel, R., 2008, "Influence of a Broken-Away TBC on the Flow Structure and Wall Temperature of an Effusion Cooled Multi-Layer Plate Using the Conjugate Calculation Method," Proceedings, ASME Turbo Expo 2008, Berlin, Germany, GT2008-50378

[8] Ho, K., Urwiller, C., Konan, S., Liu, J., Aguilar, B., 2014, "Conjugate Heat Transfer Analysis For Gas Turbine Cooled Blade," Proceedings, ASME Turbo Expo 2014, Düsseldorf, Germany, GT2014-25952.

[9] Menter, F., Esch, T., 2001, "Elements of industrial heat transfer predictions," COBEM 2001, 16th Brazilian Congress of Mechanical Engineering. 